\title{
Perencanaan Stategis Sistem Informasi Administrasi di SLBN Nunumeu SoE Menggunakan Metode Ward and Peppard
}

\author{
Anjarwanti S.R. Suseno1, Agustinus Fritz WIjaya² \\ ${ }^{1}$ Information System Departement, Satya Wacana Christian University, Salatiga, Indonesia \\ ${ }^{2}$ Information System Departement, Satya Wacana Christian University, Salatiga, Indonesia \\ Email: 1682017074@student.uksw.edu, 2agustinus.wijaya@uksw.edu
}

\begin{abstract}
Special education school is a school established by the government with a special concept for Children with Special Needs. In carrying out activities, there is an Administration section which is an important part of the process of activities at school, but there are obstacles, namely not being well systemed so that it creates difficulties in operating. In building a good system, it is necessary to have a Strategic Information System planning in advance, therefore this research was conducted. This research was conducted using the Ward and Peppard method and using the SWOT, Value Chain, and MCFarland Strategy analysis methods, with qualitative research methods, then providing output in the form of proposed applications to be considered in future application development in order to facilitate all activities in the administrative section of SLBN Nunumeu.
\end{abstract}

Keywords: Ward and Pepapprd, SWOT, Value Chain, MCFarland Startegic

\section{PENDAHULUAN}

Pemerintah Indonesia mendirikan Sekolah luar Biasa Negeri (SLBN) dengan konsep khusus bagi Anak Berkebutuhan Khusus (ABK). SLBN memiliki konsep tersendiri dalam pendidikan. Dimulai dengan kurikulum yang dibuat sesuai dengan kebutuhan khusus masing-masing siswa yang ada dan penyesuaian fasilitas, sedangkan metode pembelajaran yang dilakukan hampir mirip dengan sekolah regular. Namun tetap membutuhkan kemampuan setiap pengajar untuk menyesuaikan dengan 
Vol. 1, No. 3, September 2020 e-ISSN: 2775-2496

https://journal-computing.org/index.php/journal-cisa/index

kebutuhan khusus siswa tersebut. SLBN Nunumeu SoE adalah salah satu SLBN yang ada di Kabupaten TTS khususnya daerah Kota SoE.

Dalam tatanan proses di SLBN Nunumeu SoE, terdapat bagian Administrai yang bertugas mengurus segala keperluan administrasi milik siswa,guru dan sekolah. Namun karena belum adanya Sistem Informasi dalam adminitrasi di SLBN Nunumeu SoE, menjadikan proses administrasi milik siswa,guru dan sekolah tidak tersistem dengan baik, sehingga terjadi kesulitan ketika administrasi tersebut dibutuhkan baik untuk kebutuhan siswa, guru ataupun sekolah. Bagian administrasi mengembang berbagai tugas yang berhubungan dengan data seperti : data siswa dan guru, data asset sekolah, data akreditasi dan masih banyak lagi. Banyaknya data yang ada bila tidak tersistem dengan baik maka akan memberikan kerugian tersendiri, hal ini menjadi dasar bagi penulis untuk melakukan penelitian dan membuat perencanaan strategi Sistem Informasi khususnya pada bagian administrasi yang kemudian akan memberikan usulan aplikasi guna memperbaiki sistem informasi sekolah khususnya dia bagian administrasi untuk lebih baik kedepannya.

Perencanaan strategis informasi adalah suatu proses menyeluruh dan sistematis untuk merumuskan tujuan dan sasaran perusahaan/ organisasi serta menentukan strategi yang memanfaatkan keunggulan system informasi [1]. Perencanaan strategis system informasi dilakukan untuk mencapai tujuan-tujuan yang dimiliki oleh organisasi dan perusahaan, perencanaan strategis system informasi perlu dilakukan sebelum pembangunan system informasi itu sendiri sehingga kemudian dapat sesuai dengan titik tuju yang diinginkan dan tepat sasaran.

\section{METODOLOGI PENELITIAN}

Metodologi penelitian yang digunakan adalah Metode Kualitatif. Metode Kualitatif adalah kebalikan dari metode Kuantitatif yang memuat data dalam bentuk hitungan atau statistik, Metode Kualitafif mengarah kepada penjelasan secara deskriptif tentang sesuatu yang di amati atau yang diteliti. 
Vol. 1, No. 3, September 2020 e-ISSN: 2775-2496

https://journal-computing.org/index.php/journal-cisa/index

\subsection{Metode Penelitian}

Proses penelitian ini menggunakan Metode Ward and peppard. Metode Ward and peppard adalah metodelogi yang ditemukan oleh John and Joe Peppard pada tahun 2002, metode ini termaksud dalam kategori menyeluruh, yang diawali dengan kegiatan penilaian dan pemahaman posisi perusahaan atau organisasi masa sekarang yang kemudian dapat digunakan untuk penentuan perencanaan dan strategi di masa yang akan datang [2].

Penelitian diawali dengan proses pengambilan data dalam bentuk wawancara dan observasi, dimana peneliti melakukan tanya jawab secara langsung dengan beberapa pihak dari SLBN Nunumeu SoE yakni bersama Kepala Sekolah dan Pegawai di bagian Administrasi. Setelah data didapat melalui proses wawancara yang dilakukan, selanjutnya masuk dalam tahap dan proses menganalisa keadaan Lingkungan SLBN Nunumeu SoE khususnya pada bagian administrasi dengan menggunakan metode analisa Value Chain dan SWOT.

Setelah Proses analisa keadaan Lingkungan SLBN Nunumeu SoE khususnya pada bagian administrasi dilanjutkan dengan proses pemetaan aplikasi bagi bagian administrasi, pemetaan aplikasi difungsikan untuk memetakan aplikasi apa saja yang harus dimiliki oleh bagian administrasi demi mendukung proses alur aktivitas yang ada. Pemetaan aplikasi dilakukan dengan menggunakan metode analisis MCFarland Startegic. Pemetaan kebutuhan aplikasi dilakukan dengan membagi kedalam empat kuadran (strategic, high potential, key operation, and support) sesuai dengan kebutuhan dan fungsi. Aplikasi tersebut. Proses pemetaan Aplikasi kemudian dilanjutkan dengan proses rencana implementasi guna memetakan waktu pengimplementasian aplikasi yang ada sesuai dengan kebutuhan yang paling mendesak bagi SLBN Nunumeu khususnya pada bagian Adminitrasi[3]. Bagan tahapan penelitian tertera pada gambar 1.1 
Vol. 1, No. 3, September 2020 e-ISSN: 2775-2496

https://journal-computing.org/index.php/journal-cisa/index

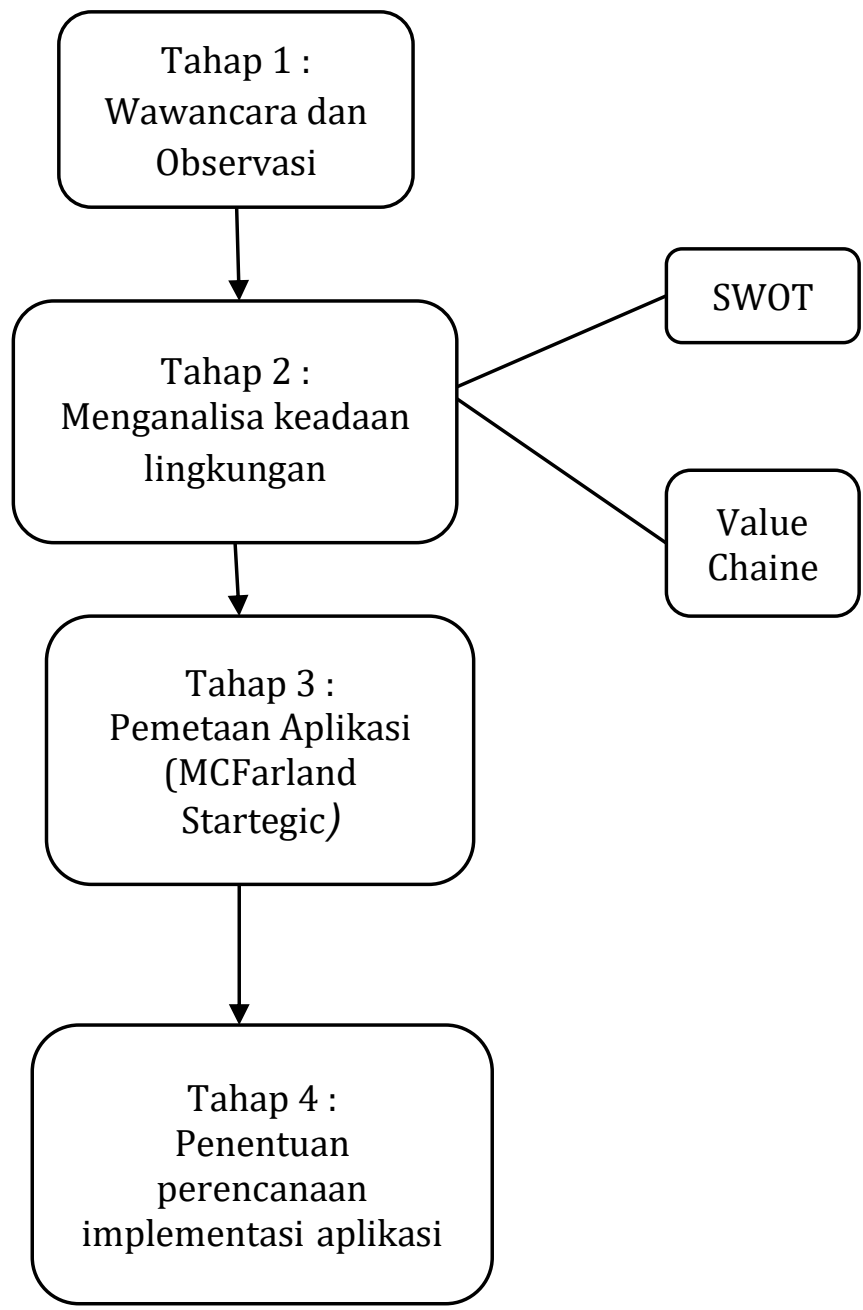

Gambar 1. Tahapan Penelitian

\section{HASIL DAN PEMBAHASAN}

Setelah proses wawancara dan observasi dilakukan, data yang didapat kemudian diolah dan digunakan untuk menganalisa keadaan lingkungan sekitar SLBN Nunumeu SoE khusunya di pada bagian Administrasi, Pemetaan aplikasi dan rencana Implementasi untuk membangun aplikasi yang diusulakan. 
Vol. 1, No. 3, September 2020 e-ISSN: 2775-2496

https://journal-computing.org/index.php/journal-cisa/index

\subsection{Analisa Ruang Lingkup}

Proses Analisa Ruang Lingkup dilakukan menggunakan dua metode analisa yakni Value Chain dan SWOT.

\subsubsection{Value Chain}

Value Chain adalah salah satu metode analisis yang dapat dilakukan untuk menganalisis aktivitas yang ada dalam perusahaan atau lembaga.analisa Value Chain ini berguna untuk menggambarkan kegiatan apa saja yang ada didalam organisasi tersebut dan sekelilingnya, dan menghubungkan kegiatan yang ada ke dalam analisa kekuatan oraganisasi yang kompetitif [4]. Berikut adalah hasil analisis value chain di SLB Nunumeu khususnya dibagian administrasi.

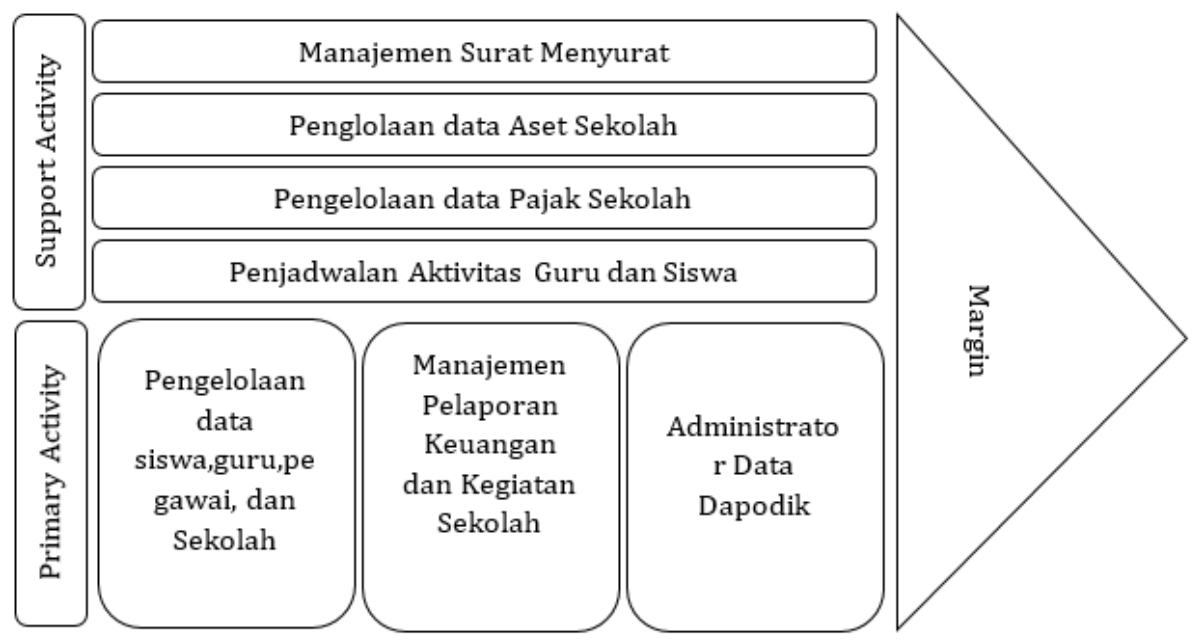

Gambar 2. Value Chain Bagian Administrasi SLB Nunumeu

Berikut adalah hasil analisa dengan nmenggunakan metode Value Chain. Seluruh kegiatan yang ada di bagian administrasi SLB Nunumeu di kelompokan kedalam dua jenis akitivitas yakni primary activity dan support Activity,rinciannya sebagai berikut:

a. Primary Activity

1. Pengelolaan data siswa,guru dan Sekolah 
Vol. 1, No. 3, September 2020 e-ISSN: 2775-2496

https://journal-computing.org/index.php/journal-cisa/index

2. Manajemen Pelaporan Keuangan dan Kegiatan Sekolah

3. Administrator Data Dapodik

b. Support Activity

1. Manajemen Surat Menyurat

2. Pengelolaan data asset Sekolah

3. Pengelolaan Data pajak Sekolah

4. Penjadwalan Aktivitas Guru dan Siswa

\subsubsection{Analisa SWOT}

Metode Analisa SWOT merupakan sebuah alat untuk mendefinisikan kekuatan, kelemahan, kesempatan, dan ancaman yang ada pada sebuah perusahaan (Ward and Peppard 2002). Analisa SWOT (Strength, Weakness, Opportunities, Threats) digunakan dalam proses menilai kekuatan dan kelemahan dari sumber daya yang dimiliki serta kesempatan dan tantangan yang datang dari eksternal perusaan atau organisasi [5]. Analisa SWOT dibagi menjadi 4 Kategori yakni Strength (Kekuatan),Weekness (Kelemahan),Oppurtunity (Peluang),dan Threats (Ancaman). Stength dan weekness digunakan untuk melihat kekuatan dan kelemahan yang dimiliki oleh perusahaan/lembaga secara internal. Sedangkan Oppurtunity dan Threats digunakana untuk melihat Peluang dan ancaman yang diberikan oleh eksternal perusahaan/lembaga. Berikut bagan SWOT Bagian Administrasi SLB Nunumeu. Berikut table SWOT dari bagian administrasi SLB Nunumeu :

Tabel 1. Tabel Analisa SWOT Bagian Administrasi SLB Nunumeu

\begin{tabular}{|c|c|}
\hline STRENGTH & WEEKNESS \\
\hline $\begin{array}{l}\text { - Sebagai pusat data di SLB } \\
\text { Nunumeu }\end{array}$ & $\begin{array}{l}\text { - Kekurangan Pegawai Khusus } \\
\text { bagian administrasi }\end{array}$ \\
\hline 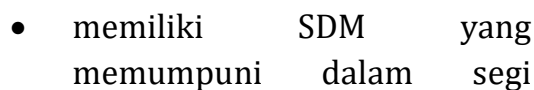 & $\begin{array}{l}\text { - Data-data yang dimiliki tidak } \\
\text { lengkap dan tidak teratur }\end{array}$ \\
\hline pengetahuan & - Kurangnya \\
\hline - memiliki Fasilitas sistem & administarsi \\
\hline informasi yang baik & - Belum adanya integrasi data \\
\hline OPPURTUNITY & THREATS \\
\hline
\end{tabular}


Vol. 1, No. 3, September 2020 e-ISSN: 2775-2496

https://journal-computing.org/index.php/journal-cisa/index

\begin{tabular}{lrrl}
\hline \multicolumn{2}{c}{ STRENGTH } & \multicolumn{2}{c}{ WEEKNESS } \\
\hline Sekolah mendukung & penuh & & Kurangnya SDM dalam \\
pembangunan & dan & & pembuatan aplikasi \\
pembaharuan sistem & bagi & $\bullet$ & $\begin{array}{l}\text { tidak ada aturan khusus dari } \\
\text { Bagian administrasi. }\end{array}$ \\
& & & $\begin{array}{l}\text { sekolah mengenai pembagian } \\
\text { Jobdesc Bagian Administrasi }\end{array}$ \\
& & & \\
& &
\end{tabular}

Pada table 1.1 menggambarkan analisa SWOT bagian administrasi SLB Nunumeu, berikut dirumuskan Perencanaan Strategis Sistem Informasi yang ada :

a. Mengembangkan kekuatan dan mengoptimalkan peluang (S-O) Pembuatan Sistem Informasi bagi Bagian adminitrasi SLB Nunumeu dengan memanfaatkan seluruh fasilitas Sistem Informasi yang tersedia dan SDM yang memumpuni dalam proses pengoperasian serta menggunakan dukungan dari sekolah dalam proses izin dan pendanaan

b. Mengembangkan kekuatan untuk mengatasi ancaman (S-T)

1. Pembuatan SOP Jobdesc dan SOP bagian Administrasi dengan mengoptimalkan SDM yang ada serta berbagai fasilitas Sistem Informasi yang mendukung.

2. Melakukan kerja sama dengan Pihak pembuatan Aplikasi dengan memanfaat kan kekuatan bagian administrasi sebagai pusat data SLB NUunumeu yang memerlukan Aplikasi dalam pemenuhan kebutuhan dan keberlangsungan aktivitas yang ada.

c. Meminimalkan kelemahan untuk memanfaatkan peluang (W-O)

1. Membangun aplikasi-aplikasi yang saling berintergrasi didalam bagian administrasi SLB Nunumeu agar datadata yang ada dapat teratur dan kelengkpaan data terpenuhi dengan memanfaatkan dukungan pihak sekolah dalam pembangunan aplikasi yang dibutuhkan.

2. Perekrutan tambahan Tenaga adimistrasi bagi bagian administrasi sesuai dengan kebutuhan jobdesc tang tersedia dengan menggunakan seluruh dukungan pihak Sekolah dalam melakukan perekrutan dan penggajian 
Vol. 1, No. 3, September 2020 e-ISSN: 2775-2496

https://journal-computing.org/index.php/journal-cisa/index

d. Meminimalkan kelemahan dan menghindari ancaman (W-T)

Bagian administrasi mengoptimalkan sistem informasi yang dibangun untuk pengorganisasian dan pengintergrasian data serta melakukan pengkoordinasian pembagian Jobdesc kepada pihak sekolah sesuai dengan pembangunan sistem informasi yang dilakukan.

\subsection{Pemetaan Aplikasi}

Metode MCFarland Startegic adalah salah satu metode analisis untuk menentukan pemetaan aplikasi bagi organisasi atau perusahaan. Grid McFarlan Strategic Grid digunakan untuk memetakan aplikasi system informasi berdasarkan kontribusinya terhadap perusahaan [6]. Pemetaan menggunakan metode ini dengan cara aplikasi di kategorikan berdasarkan fungsi dari setiap aplikasi yang ada, dan dikelompokan menjadi 4 kategori yakni :

1. Strategic

Aplikasi yang penting guna mempertahankan Strategi bisnis di masa yang akan datang

2. High Potential

Aplikasi penting yang memungkinkan dalam pencapaian kesuksesan di masa yang akan datang

3. Key Operational

Aplikasi saat ini yang menjadi ketergantungan kesuksesan

4. Support

Aplikasi yang bernilai tapi tidak menjadi pusat ketegantungan untuk kesuksesan

Tabel 2. Pemetaan Aplikasi Menggunakan MC Farland Strategic

\begin{tabular}{c|c}
\hline Strategic & High Potential \\
\hline Aplikasi pengarsipan & Aplikasi Dapodik \\
Aplikasi pelaporan & Website Sekolah \\
Aplikasi aset sekolah & \\
\hline Aplikasi Pengolahan Data & Aplikasi penjadwalan dan Kehadiran \\
siswa,sekolah, dan guru & Support \\
\hline Key Operational &
\end{tabular}


Vol. 1, No. 3, September 2020 e-ISSN: 2775-2496

https://journal-computing.org/index.php/journal-cisa/index

Berdasarkan tabel diatas terdapat 7 aplikasi yang diusulkan dan telah dikelompokan ke dalam masing-masing kategori sesuai kontribusi setiap aplikasi. Aplikasi Pengarsipan, Aplikasi Pelaporan dan Aplikasi aset sekolah dikatergorikan ke dalam Srategic dikarenakan kontribusinya yang penting dalam mempertahakan seluruh aspek Aktivitas di bagian Adminstrasi sehingga data yang ada dapat terarsip.terlaporkan dengan baik, demikian pula dengan data asset sekolah guna menjaga setip perkembangan asset sekolah. Aplikasi Dapodik dan website sekolah dikategorikan ke dalam High Potential di karenakan aplikasi yang akan mendukung pencapaian bagian adminstrasi yang lebih baik dan juga dalam kegiatan publikasi sekolah sendiri. Aplikasi Pengolahan Data Siswa,sekolah dan Guru di kategorikan ke dalam Key Oprational sbeagai kunci dalam segala aktivitas didalam bagian administrasi dan karena kemudian dapat menjadi pusat data utama dan yang terpenting. Aplikasi Penjadwalan dan Kehadiran di katergorikan ke dalam Suporrt dengan tujuan melengkapi dan menyempurnakan Sistem Informasi didalam aktivitas Bagian Administrasi.

\subsection{Rencana Implementasi}

Sesuai dengan proses pemetaan aplikasi yang terlah dilakukan, aplikasi tesebut kemudian di masukan ke dalam rencana Implementasi. Rencana implementasi ini dibuat dengan tujuan mengkategorikan waktu pembangunan atau rencana implementasi sesuai dengan skala prioritas Implementasi [7], sehingga pembangunan dilakukan berdasarkan aplikasi yang paling dibutuhkan terlebih dahulu. Berikut adalah Rencana Implementasi aplikasi yang di masukan kedalam masing-masing skala prioritas :

Tabel 3. Tabel Rencana Implementasi

\begin{tabular}{llll}
\hline No & \multicolumn{1}{c}{ Rekomendasi Aplikasi } & \multicolumn{3}{c}{ Skala Prioritas Implementasi } \\
\hline 1. & $\begin{array}{l}\text { Aplikasi Pengolahan Data } \\
\text { siswa,sekolah, dan guru }\end{array}$ & & \\
2. & Aplikasi pengarsipan & & \\
3. & Aplikasi pelaporan & & \\
\end{tabular}


Vol. 1, No. 3, September 2020 e-ISSN: 2775-2496

https://journal-computing.org/index.php/journal-cisa/index

\begin{tabular}{|c|c|c|}
\hline No & Rekomendasi Aplikasi & Skala Prioritas Implementasi \\
\hline & & $\begin{array}{ll}\text { I } & \text { II } \\
\end{array}$ \\
\hline 4. & Aplikasi aset sekolah & \\
\hline 5. & Aplikasi Dapodik & \\
\hline 6. & Website Sekolah & \\
\hline 7. & Aplikasi penjadwalan dan Kehadiran & \\
\hline
\end{tabular}

\section{KESIMPULAN}

Dalam semua proses analisa yang telah dilakukan, Bagian Adminstrasi SLB Nunumeu perlu mengadakan Pembangunan sistem Informasi guna mempelancar aktivitas yang ada. \& aplikasi telah di usulkan yakni : Aplikasi Pengolahan Data siswa,sekolah, dan guru, Aplikasi pengarsipan, Aplikasi pelaporan, Aplikasi aset sekolah, Aplikasi Dapodik, Website Sekolah, dan Aplikasi penjadwalan dan Kehadiran, semua aplikasi ini harus dintergrasikan satu sama lain sehingga semua data yang ada dapat saling berintegrasi dan dibangun berdasarkan kebutuhan atau skala prioritas impelmentasi. Selain dari pada aplikasi yang ada perlu perlu adanya SOP dalam melaksanakan aktivitas di SLB Nunumeu SoE.

\section{DAFTAR PUSTAKA}

[1] I. Supriyantoko, "Perancangan Strategis Sistem Informasi di Smk Diponegoro 1 Jakarta," Elinvo (Electronics, Informatics, Vocat. Educ., vol. 3, no. 2, pp. 10-18, 2019, doi: 10.21831/elinvo.v3i2.21862.

[2] J. Ward and J. Peppard, "Strategic Planning for Information System."

[3] A. Wedhasmara, "Langkah-Langkah Perencanaan Strategis," J. Sist. Inf., vol. 1, no. 1, pp. 14-22, 2009.

[4] P. Strategis et al., "Metode Ward and Peppard ( Studi Kasus : Dinas Kependudukan Dan Pencatatan Sipil Kota Tomohon )," Perenc. Strateg. Sist. Inf. Menggunakan Metod. Ward Peppard (Studi Kasus Dinas Kependud. Dan Pencatatan Sipil Kota Tomohon), vol., no., pp. 604-610. 
https://journal-computing.org/index.php/journal-cisa/index

[5] D. H. Utama, M. N. N. Sitokdana, and A. F. Wijaya, "Perencanaan Strategis Sistem Informasi dan Teknologi Informasi E-Agribusiness pada PT Trubus Yogyakarta," Aiti, vol. 15, no. 2, pp. 99-106, 2018, doi: 10.24246/aiti.v15i2.99-106.

[6] A. Heriadi, M. Suyanto, and S. Sudarmawan, "Perencanaan Strategis Sistem Informasi STMIK Cahaya Surya Kediri," Creat. Inf. Technol. J., vol. 1, no. 1, p. 15, 2015, doi: 10.24076/citec.2013v1i1.6.

[7] E. Cres, C. Yobel, and N. Ngalumsine, "Ward and Peppard Di Perusahaan Pt Pura Barutama ( Unit Pm10 )," pp. 113-119. 